\title{
La reparación de las víctimas en la jurisprudencia de la Corte Penal Internacional
}

\author{
Reparation of victims in the jurisprudence \\ of the International Criminal Court \\ A reparação das vítimas na jurisprudência \\ do Tribunal Penal Internacional
}

La réparation des victimes dans la jurisprudence de la Cour pénale internationale

国际刑事法院判例中的受害者赔偿

Ezequiel Rodrigo Galván ${ }^{1} \mid \begin{aligned} & \text { Universidad Nacional } \\ & \text { de La Plata, Argentina }\end{aligned}$

Revista Derechos en Acción ISSN 2525-1678/ e-ISSN 2525-1686

Año 4/No 13, Primavera 2019 (21 septiembre a 20 diciembre), 423-450

DOl: https://doi.org/10.24215/25251678e345

ORCID: https://orcid.org/0000-0003-0833-4366

Recibido: 14/06/2019

Aprobado: 24/08/2019

Resumen: El trabajo aborda la reparación en la jurisprudencia de la Corte Penal Internacional que -a partir del Estatuto de Roma- dispuso el reconocimiento de las víctimas y su reparación en el marco de una instancia internacional encargada de juzgar responsabilidad individual por los "crímenes más graves de transcendencia internacional". Concluye el autor que la víctima y su dignidad se presenta como un actor y elemento de sentido transversal a todo el sistema derivado del Estatuto de Roma, el cual recupera al derecho internacional de los derechos humanos como una fuente de derecho, así como la jurisprudencia de

\footnotetext{
1 Abogado (UNLP). Escribano (UNLP). Diplomado en DESC (UM). Maestrando en Derechos Humanos (IDH-UNLP). Alumno de la Diplomatura en Derechos del Consumidor y Procesos Protectorios (U.N.). Email: ezequielrgalvan@gmail.com .
} 
sus tribunales internacionales como una interpretación de ese derecho que integra al Estatuto. La recepción expresa de estándares de la Corte Interamericana y de la Corte Europea de Derechos Humanos, además de aprovechar el camino recorrido por estos tribunales internacionales, incorpora a la Corte Penal Internacional en el diálogo de estas instancias jurisdiccionales y la construcción del corpus iuris de los derechos humanos a partir de concepción común de la preeminencia de la dignidad de la persona

Palabras claves: Corte Penal Internacional-reparación-víctimas-derecho procesal

Abstract: The work deals with reparation in the jurisprudence of the International Criminal Court, which -based on the Rome Statute- provided for the recognition of victims and their reparation within the framework of an international body in charge of judging individual responsibility for the "most serious crimes of international transcendence". The author concludes that the victim and his dignity is presented as an actor and element of meaning transversal to the entire system derived from the Rome Statute, which recovers international human rights law as a source of law, as well as the jurisprudence of its international tribunals as an interpretation of that right that integrates the Statute. The express reception of standards of the Inter-American Court and the European Court of Human Rights, in addition to taking advantage of the path traveled by these international tribunals, incorporates the International Criminal Court in the dialogue of these jurisdictional instances and the construction of the corpus iuris of human rights based on a common conception of the pre-eminence of the dignity of the person.

Keywords: International Criminal Court-reparation-victims-procedural law

Resumo: 0 trabalho aborda a reparação na jurisprudência do Tribunal Penal Internacional que - a partir do Estatuto de Roma - ordenou 0 reconhecimento das vítimas e sua reparação no âmbito de uma instância internacional responsável de julgar responsabilidade individual pelos "crimes mais graves de transcendência internacional". 0 autor conclui que a vítima e sua dignidade são apresentadas como ator e elemento de significado transversal a todo o sistema derivado do Estatuto 
de Roma, que recupera o direito internacional dos direitos humanos como fonte de direito, assim como a jurisprudência de seus tribunais internacionais como uma interpretação desse direito que integra 0 Estatuto. A recepção expressa dos padrões da Corte Interamericana e da Corte Européia de Direitos Humanos, além de aproveitar o caminho adotado por essas cortes internacionais, incorpora a Corte Penal Internacional no diálogo dessas instâncias jurisdicionais e na construção do corpus iuris dos direitos humanos com base em uma concepção comum da preeminência da dignidade da pessoa.

Palavras-chave: Tribunal Penal Internacional - reparação - vítimas - direito processual

Résumé: Le travail aborde le thème de la réparation dans la jurisprudence de la Cour pénale internationale qui -à partir du statut de Rome- a reconnu le droit des victimes et leur droit à une réparation dans le cadre d'un organe international chargé de juger de la responsabilité individuelle dans les cas de "crimes les plus graves de portée internationale". L'auteur conclut que la victime et sa dignité se présentent comme un acteur et un élément de signification transversale à tout le système résultant du statut de Rome, qui reprend le droit international des droits de l'homme comme une source du droit, ainsi que la jurisprudence de ses tribunaux internationaux comme une interprétation de ce droit qui intègre le statut. La réception expresse des normes de la Cour Interaméricaine et de la Cour Européenne des droits de l'homme, en plus de profiter du chemin parcouru par ces juridictions internationales, permet d'intégrer la Cour pénale internationale dans le dialogue avec ces instances juridictionnelles et la construction d'un corpus iuris des droits de I'homme sur la base d'une conception commune de la prééminence de la dignité de la personne.

Mot-clés: Cour Pénale Internationale, réparation, victimes, droit procédural

摘要: 这项工作涉及国际刑事法院判例的赔偿 (根据《罗马规约》), 该 判决下令在一个国际机构的框架内承认受害者及其赔偿, 该机构负 责对 “最严重的犯罪” 承担个人责任。具有国际意义”。作者得出的结 论是, 受害人及其尊严被作为行为者和横向意义的要素呈现在源自 《罗马规约》的整个体系中, 该规约恢复了国际人权法作为法律渊 源以及法治的判例。其国际法院是对包含《规约》的这项权利的解 
释。美洲法院和欧洲人权法院对标准的明确接受, 除了利用这些国 际法院所采取的途径外, 还把国际刑事法院纳入了这些管辖权案件 的对话和国际刑事法院的主体构造。基于对人的尊严至高无上的共 同观念的人权

关键字: 国际刑事法院-赔偿-受害者-程序法

\section{Introducción}

Uno de los aspectos más relevantes de la creación de la Corte Penal Internacional a partir del Estatuto de Roma (1998) es el reconocimiento de las víctimas y su reparación en el marco de una instancia internacional encargada de juzgar responsabilidad individual por los "crímenes más graves de transcendencia internacional".

En este aspecto, el Tratado de creación, así como la posterior práctica de este tribunal de justicia internacional penal, recuperan a la persona afectada y su dignidad como una dimensión central de su labor y sentido de existencia, que a su vez se presenta, en algunos aspectos, como una experiencia superadora de otras instancias internacionales que disponen la recomposición de las personas afectadas por los hechos juzgados (sistemas de protección de derechos humanos). ${ }^{2}$

Ante esto, el objeto del presente trabajo es analizar cómo está contemplada la reparación de las víctimas en el marco del procedimiento ante la Corte Penal Internacional y los estándares desarrollados en su jurisprudencia a partir de los casos "Lubanga" y su apelación, "Katanga" y "Al Mahdi", las medidas de reparación dispuestas y su proceso de construcción.

2 Un ejemplo interesante es la protección de las víctimas y su integridad (en un sentido amplio) dentro de la tramitación del proceso, especialmente el contemplar un cuerpo profesional para el acompañamiento de testigos y víctimas, especialmente de la violencia sexual (art. 43 inc. 6), aspecto que marca una perspectiva de género que el procedimiento ante el Sistema Interamericano de Derechos Humanos no contempla y se presentan como revictimizantes de la persona. 


\section{La reparación de las víctimas dentro del proceso ante la Corte Penal Internacional}

La reparación de las víctimas de los crímenes que son juzgados por la Corte Penal Internacional está expresamente receptada en el Estatuto de Roma, específicamente en su artículo 75, estableciendo el carácter amplio de la reparación ${ }^{3}$, las personas alcanzadas (víctimas o causahabientes) ${ }^{4}$, de oficio o a solicitud, determinando el alcance y magnitud de los daños, pérdidas o perjuicios, contemplando expresamente la expresión "reparación adecuada" de la víctima, creando un Fondo Fiduciario (art. 79) destinado a la reparación de las víctimas y sus familias, y estableciendo la obligatoriedad de los Estados Partes de cumplir e implementar las medidas de reparación ordenadas 5 .

Como se puede observar, el Estatuto de Roma tiene un concepto de reparación amplio en pos de recomponer las consecuencias de los crímenes juzgados, criterio que sostienen las Reglas de Procedimiento y Prueba dictadas por la Asamblea de Estados partes.

En este aspecto, la regla 94 establece la posibilidad de las víctimas de presentar las solicitudes de reparación sin interceder como parte en el proceso; la regla 95 establece que, actuando la Corte de oficio, se notifique a las víctimas, Estados y personas afectadas a efectos que se pronuncien al respecto; la regla 96 establece el carácter central de la "publicidad de las actuaciones de reparación".

3 "incluidas la restitución, la indemnización y la rehabilitación".

4 Cabe resaltar que, además del concepto amplio de "víctima" ante esta instancia internacional, reconocer a los causahabientes como personas a reparar sin tener que considerarlas "víctimas" es algo novedoso respecto de los sistemas de protección de derechos donde la medida de recomposición se circunscribe a quien se considera víctima (acreditada) en el proceso (ej. ColDH "Cuscul Pivaral y otros vs. Guatemala" sentencia 23/08/2018, párrafo 29).

5 El art. 75 inc. 5 les asigna a estas medidas de reparación el mismo estatus que las medidas del art. 109 (obligación de los Estados Partes de efectivizar decomisos y multas), reafirmando su carácter de obligatorias en un tratado que no admite reservas (art. 120). 
En cuanto a la reparación en sí, la regla 97 estable la posibilidad de disponer reparaciones individuales, colectivas o ambas, realizar peritajes para determinar la entidad de los daños (usado en un concepto amplio), estableciendo en todo momento una participación amplia de las víctimas, sus representantes o los Estados, y respetando los derechos de las víctimas y del condenado.

Así mismo, la regla 98 establece las reparaciones individuales ${ }^{6}$ son a cargo del condenado, su depósito en el Fondo Fiduciario como mecanismo de conservación del pago individual y las disposiciones relativas al destino de los recursos del Fondo Fiduciario en beneficio de las víctimas; y, la regla 219 reafirma este carácter imperativo para los Estados Partes de las medidas de reparación ordenadas por la Corte ("No modificación de las órdenes de reparación").

Cabe destacar que el diseño actual reparación de víctimas representa en la práctica un verdadero sistema de "responsabilidad civil" en el marco de una instancia internacional que juzga responsabilidad penal, el cual recepta los rasgos distintivos de los procesos colectivos de las jurisdicciones nacionales:

(a) condena con medidas reparación de las consecuencias con identidad de causa y responsable ${ }^{7}$ (Verbic, 2017:313) sean estructurales, colectivas o individuales homogéneas ${ }^{8}$.

(b) representación de un colectivo o grupo afectado9 (Verbic, 2017:314).

(c) publicidad del proceso a efectos de anoticiar y/o convocar a los interesados (Verbic, 2017:326-327).

\footnotetext{
6 Así también las colectivas en tanto que se traduzcan en un pago (inc. 3).

7 Consecuencias de los crímenes (causa común) del condenado (responsable común).

8 Se diferencia lo estructural (ej. medidas de reconstrucción social), lo colectivo en tanto bien común indivisible (ej. reparación del ambiente), así como lo individual homogéneo (ej. la indemnización individual de cada persona pero que responde a la causa común: el crimen juzgado).

9 En este caso, las víctimas y causahabientes de los crímenes juzgados (quienes aprovechan los efectos de la sentencia condenatoria).
} 
(d) mecanismos de implementación -eficacia de la sentencia- ${ }^{10}$ (Verbic, 2017: 350-351 y 362-363).

En este aspecto, el proceso ante la Corte Penal Internacional emite una sentencia que se pronuncia sobre la responsabilidad del condenado por determinados crímenes (hechos), y, además de las medidas de reparación estructural o colectivas que puede disponer el tribunal, cada víctima o causahabiente tiene que acreditar ante la Corte su afectación, relación causal con el hecho, y entidad del daño / medidas particulares de reparación (pagos, devolución de bienes, rehabilitación, otras).

La reparación de la víctima se presenta como uno de los sentidos de la existencia de la Corte Penal Internacional (desde el propio Estatuto de Roma), criterio que expresa el tribunal ya en su primera sentencia (en materia de reparaciones) de la Sala de Primera Instancia en el caso "Lubanga Dyilo" (07/08/2012): "[...] el éxito de la Corte está, hasta cierto punto, relacionado con el éxito de un sistema de reparación." (Martínez Ventura, 2014:347).

Así mismo, se presenta como paradigmático el instituto de la reparación de las víctimas, en tanto personas individuales, en el marco de la Corte Penal Internacional dentro los tribunales internacionales que disponen medidas de reparación individual (sistemas de protección de derechos humanos) en tanto que, mientras las otras instancias internacionales (juzgando responsabilidad estatal) disponen medidas de reparación de alcance restrictivo ${ }^{11}$ (descontando las colectivas o estructurales por su carácter indivisible) y haciendo eje en las medidas de "no repetición" de la conducta lesiva por parte del Estado responsable (Bruno, 2013:55), la propia lógica de la responsabilidad penal por los crímenes que la comunidad internacional considera de mayor gravedad genera un sistema de reparación contrario, donde el eje es la reparación

10 Cómo se expone, el Estatuto de Roma y las Reglas de Procedimiento y Prueba establecen mecanismos para asegurar la efectividad de las medidas de reparación ordenadas, ej. la creación de un Fondo Fiduciario, el depósito de los pagos para su distribución, la obligación de los Estados Partes de efectivizar medidas de reparación, entre otras.

11 Solo a las "víctimas" con un concepto muy acotado de quien reviste esta condición. 
generalizada de las personas afectadas, entendiendo a la propia persecución penal del crimen como la medida de no repetición dentro de la comunidad internacional. ${ }^{12}$

\section{III. ¿Quién es víctima ante la Corte Penal Internacional?}

Teniendo presente que los sistemas de reparación de instancias internacionales están destinados a las víctimas (o sus causahabientes), el alcance de las medidas de reparación, en una dimensión personal, está dado por el propio concepto de "víctima" que maneje la instancia internacional, es decir, las personas respecto de las cuales se podrá disponer la reparación.

Cómo primer aspecto, debe destacarse que el Estatuto de Roma no tiene una definición de víctima, definiéndose en las Regla (de Procedimiento y Prueba) 85 que se considerará como tal a (a) toda persona humana "que hayan sufrido un daño como consecuencia de la comisión de algún crimen de la competencia de la Corte"13; o (b) "las organizaciones o instituciones que bayan sufrido daños directos a alguno de sus bienes que esté dedicado a la religión, la instrucción, las artes, las ciencias o la beneficencia y a sus monumentos históricos, hospitales $y$ otros lugares y objetos que tengan fines humanitarios". ${ }^{14}$

\footnotetext{
12 "Según se consigna en el preámbulo del ECPI, la Corte debe su creación al interés explícito de la comunidad internacional en erradicar la impunidad de los crímenes internacionales. (...) El juzgamiento también procura otras cosas: (...) disuadir a futuros dictadores que se propongan cometer esos crímenes aberrantes; restablecer y afianzar la paz entre los pueblos, etcétera " (Nanzer, 2014:92-93).

13 El alcance del concepto de "daños" no es una cuestión resuelta dentro del sistema, conviviendo posiciones restringidas (ej. Sala de Cuestiones Preliminares: "físicos, psicológicos y materiales") con posiciones más comprensivas (ej. Sala de Primera Instancia: "las lesiones físicas o mentales, el sufrimiento emocional, las pérdidas económicas y el menoscabo sustancial de los derechos fundamentales son todas formas pertinentes de daño") (Olásolo \& Kiss, 2010:5 y 11), elemento que determina el alcance material de la condición de "víctima" dentro del sistema.
}

14 En este aspecto, el reconocimiento de la persona jurídica, sentido que le reconoce la Corte Penal Internacional a la Regla 85 inciso "b" (Olásolo \& Kiss, 2010:5) como sujeto que puede revestir la condición de "víctima" (reparable), teniendo presente el enfoque de derechos humanos que recepta el sistema creado por el Estatuto de Roma, es interesante 
En este aspecto, puede observarse el carácter amplio del concepto de "víctima" en el ámbito de la Corte Penal Internacional $^{15}$, incluso a efectos de reconocerle la calidad procesal de "participante" en el proceso penal, que se presenta como novedoso dentro de las instancias internacionales (Olásolo \& Kiss, 2010), receptando la concepción del derecho internacional de los derechos humanos y las experiencias de sus jurisdicciones internacionales ${ }^{16}$.

Cabe resaltar que, además de la similitud en materia de competencia para disponer medidas de reparación a favor de las víctimas, se recuperan las instancias de jurisdicción internacional creadas por los distintos tratados de derechos humanos debido a que el Estatuto de Roma expresamente establece que la aplicación e interpretación de derecho aplicable por la Corte Penal Internacional "deberá ser compatible con los derechos bumanos internacionalmente reconocidos" bajo el principio de no discriminación (art. 21 inc. 3), es decir, que establece una concepción que, además de respetuosa del debido proceso (calificado por su naturaleza penal), entiende el respeto de la dignidad de la persona como elemento transversal a toda el sistema.

este posicionamiento debido a que se encuentra siendo un ámbito de coyuntura dentro de las instancias internacionales (ColDH “Opinión Consultiva 22/16" sentencia 26/02/2016, párrafo 62), en tanto si el colectivo (persona jurídica) es un sujeto de derechos en sí, o bien, la mera confluencia de personas humanas (individuos) titulares de derechos, adhiriendo el sistema a esta primera concepción.

15 Destacan los autores que si bien actualmente está siendo materia de construcción y debate los límites de la condición de víctima en el marco de un proceso ante la Corte Penal Internación, ej. (a) la víctima indirecta, (b) la persona fallecida como "víctima" (interviniente por representación), y (c) la víctima no relacionada con los delitos imputados en tanto sean competencia de la Corte, no se recurre a restringir el concepto de "víctima" a efectos de evitar la saturación del proceso (por exceso de "participantes"), sino que "el número potencial de intervinientes en las actuaciones procesales resultaría limitado "operativamente", aunque no "conceptualmente"." (pp. 8).

16 Los autores entienden que el reconocimiento de facultades a la víctima en el marco de los procesos ante la Corte Interamericana de Derechos Humanos o la Corte Europea de Derechos Humanos han sido recuperados por el Estatuto de Roma, no así por los demás tribunales penales internaciones (Olásolo \& Kiss, 2010:16). 
En este aspecto, esta concepción marcada por la centralidad de la dignidad de la persona resignifica tanto la propia condición de víctima ${ }^{17}$, como así el sentido del proceso penal internacional para con ella, "El juzgamiento también procura otras cosas: ofrecer a las víctimas un foro que les permita difundir su martirio y recuperar así la dignidad ultrajada; legar a las generaciones venideras una reconstrucción fidedigna de lo ocurrido;" (Nanzer, 2014:93). ${ }^{18}$

Así mismo, debe resaltarse que, además de adoptar un enfoque de derechos humanos transversal a su accionar, la Corte Penal Internacional ha recurrido expresamente a la jurisprudencia (estándares) del Tribunal Europeo de Derechos Humanos (Nanzer, 2014:75-76), así como de la Corte Interamericana de Derechos Humanos, especialmente a efectos de integrar el concepto de "víctima" con el interés por la verdad y justicia (Olásolo \& Galain, 2010:421).

La importancia de esta remisión expresa, además de legitimar a los tribunales internacionales citados como intérpretes de "los derechos humanos internacionalmente reconocidos", es la incorporación (a través de la jurisprudencia interamericana) del corpus iuris de los derechos humanos ${ }^{19}$ (O'Donell, 2012:56-62)

17 Cómo se expresó, se integra el contenido de "daños" (alcance material) y "afectados" (alcance material) a partir de esta concepción, reconociendo (o discutiendo) la condición de ciertas personas como víctimas que no lo serían en sin esta perspectiva de derechos humanos. 18 Esta reformulación del proceso (penal) reconociendo a la víctima es un elemento que diferencia a la Corte Penal Internacional de los demás tribunales penales internacionales, "En efecto, el Estatuto del Tribunal Penal Internacional para la Antigua Yugoslavia (ETPY) y el Estatuto del Tribunal Penal Internacional para Ruanda (ETPR) limitan el rol de la víctima durante el proceso a la participación como testigo, en decir, como fuente de prueba. En materia de reparaciones, la facultad de los jueces de los TPY y TPR se limita a ordenar la restitución de propiedad obtenida ilícitamente a sus legítimos dueños. La Corte Especial para Sierra Leona tampoco prevé, en sus textos legales, la posibilidad participación ni les confiere a sus jueces autoridad alguna en materia de reparaciones. El ER establece que las víctimas son participantes en el proceso penal, lo cual las distingue de las partes propiamente dichas (que son la fiscalía y la defensa). Las víctimas tienen un estatuto procesal que, comparado con el de las partes, es significativamente menor." (Olásolo \& Kiss, 2010:16).

19 Entiendo al mismo como interpretación del contenido de un tratado de derechos humanos (o "los derechos humanos internacionalmente reconocidos" en este caso) recuperando los 
en el accionar del a Corte Penal Internacional, receptando e ingresando ${ }^{20}$ en este diálogo donde el concepto de "víctima" y su reparación es transversal a toda producción.

\title{
IV. La reparación de las víctimas en la primera sentencia de la Corte Penal Internacional
}

En el año 2012 la Corte Penal Internacional emitió su primera sentencia, condenado a Lubanga Dyilo por los crímenes de reclutamiento y utilización de niños soldados, en una causa con gran cantidad de víctimas, en la cual la Sala de Primera Instancia decidió (07/08/2012) no reconocer reparaciones individuales (solicitudes), sino estableció los principios, directrices y procedimientos para la reparación, delegando en el Fondo Fiduciario tanto las solicitudes individuales como la elaboración y ejecución de un plan de reparaciones colectivas, en una sentencia genérica (indeterminada) y programática, cuya complejidad de ejecución atenta contra su efectividad ${ }^{21}$ (Martínez, 2014:345-346).

\begin{abstract}
distintos tratados de derechos humanos, otros tratados con disposiciones de derechos humanos, otros instrumentos no vinculantes, y las expresiones de otros órganos internacionales (e incluso nacionales) en la construcción de sentido. En este aspecto, si la Corte Penal Internacional recurriera a la Jurisprudencia de la Corte Interamericana a efectos de reconocer la identidad de género como una dimensión de la identidad de la persona (“Opinión Consultiva 24/17", sentencia 24/11/2017) para establecer como el grupo contra el que se dirigió un crimen de lesa humanidad (ej. exterminio o persecución), ingresaría a la Corte Penal Internacional, además de la propia interpretación de la Corte Interamericana, estándares que receptan el "Informe Violencia contra Personas LGTBI" (Comisión Interamericana, $12 / 11 / 2015)$ y especialmente los "Principios de Yogyakarta", un instrumento no vinculante a partir del cual se construyen las categorías que recepta la jurisprudencia interamericana.

20 Además de la propia producción de la Corte Penal Internacional como contenido del corpus iuris de los derechos humanos, es interesante recuperar la presencia del tribunal (con una concepción amplia de la "víctima" en el proceso) como interpelación a las demás instancias internacionales respecto de su recepción de las víctimas en el proceso, y por ende, en la reparación.
\end{abstract}

21 En este aspecto, recuperando el comentario del autor, la "efectividad" de la sentencia es un aspecto sustancial a tener presente debido a que la reparación de la víctima puede no concretarse aún cuando un pronunciamiento firme le reconoce su derecho a su recomposición (preocupación tanto de las instancias internacionales como los procesos colectivos locales), 
Cómo primer aspecto importante, en la sentencia la Corte Penal Internacional (reafirmando un accionar con enfoque de derechos humanos) expresa que, además del rol central del a reparación como sentido de su labor, entiende que la reparación es un derecho a la reparación es un derecho humano reconocido por la comunidad internacional ${ }^{22}$, interpretación que establece que el proceso no se agota en la condena penal, sino en la reparación de las víctimas ${ }^{23}$.

En un segundo aspecto, la sentencia establece como los propósitos de la reparación, además de la reparación de las consecuencias por el responsable (condenado), otros objetivos del caso concreto (Martínez, 2014:348):

(a) "aliviar el sufrimiento causado por los crímenes a las víctimas individuales y a las comunidades".

(b) "costear la justicia a las víctimas mediante la disminución de las consecuencias de los crimenes".

(c) "prevenir futuras violaciones".

(d) "contribuir a la reintegración de los ex niños soldados".

(e) "ayudar a promover la reconciliación entre el condenado, las víctimas de los crimenes y las comunidades afectadas, siempre que esto último se haga voluntariamente".

Estableciendo como medidas para su concreción medidas de (a) "restitución", (b) "rehabilitación", y (c) "satisfacción", y

\footnotetext{
tornando en ilusorio el mecanismo de tutela. Recurriendo al desarrollo de la Corte Interamericana en la materia, el recurso (o mecanismo) para ser "efectivo" debe poder lograr su finalidad (Ibañez Rivas, 2014:615), en este caso, reparar las consecuencias de los crímenes condenados, motivo por el cual debe ser un eje de análisis y preocupación central en la construcción de las medidas y procedimientos de reparación, así como su seguimiento y estudio.

22 "Il]a Sala acepta que el derecho a la reparación es un derecho humano básico y bien establecido, consagrado en tratados de derechos humanos universales y regionales" (Jara, 2013:117).

23 Puede recuperarse en este sentido, como modelo orientador, el proceso ante la Corte Interamericana donde ante una sentencia condenatoria, se disponen las medidas de reparación y el proceso avanza hacia una nueva instancia que supervisa el cumplimento de la sentencia (art. 69 Reglamento de la Corte Interamericana de Derechos Humanos, 2009)
} 
(d) "garantías de no repetición" (Martínez, 2014:349) o (c) "compensación", y (d) "otras modalidades de reparación" (Jara, 2013:122). ${ }^{24}$

Así mismo, se establece como principios en la materia la "dignidad, no discriminación y no estigmatización" (Martínez, 2014:349; Jara, 2013:117), con una concepción amplia de víctima reparable ${ }^{25}$, estableciendo el carácter accesible y consultado de la reparación, el carácter especializado de las medidas de reparación $^{26}$, y la proporcionalidad de la reparación ${ }^{27}$, incorporando desde esta primera sentencia perspectiva de género en la etapa de reparaciones ${ }^{28}$.

24 Nota: atento a la insuficiente técnica del autor se recurre a las traducción y/o análisis de los autores (muchas compartidas entre los diferentes textos), sin embargo, en el presente caso se hace la salvedad atento a que no es irrelevante la diferencia de términos entre "satisfacción" y "compensación", teniendo la primera una concepción orientada a la reparación espiritual (dignidad) mientras "compensación" tiene una matiz patrimonial, destacando como ejemplo la Corte Interamericana en sus primeras sentencias no disponía "reparaciones" sino "indemnizaciones compensatorias" (Bruno, 2013::9 y 55), acompañando otros autores esta noción inmaterial o "reparación simbólica" (Lopez Martín, 2013:217-218). Así mismo, la diferencia entre "medidas de no repetición" y "otras modalidades de repetición" es conceptualmente sustancial. En todo caso, la traducción de Martínez (de ser correcta) da cuenta de una recepción de la Corte Penal Internacional (desde la primera sentencia) de la tradición interamericana en la materia, la cual es la más comprensiva de la instancia de reparación dentro de las jurisdicciones internacional.

25 "[... ] la noción de las víctimas en el sistema de la CPI es multifacética; tiene muchos aspectos de los que emergen diferentes criterios de clasificación de víctima, como persona natural o jurídica, directa o indirecta, relacionada con el caso o situacional. El mandato de reparación a las víctimas dado a la CPI cubre a todas las clases de víctimas" (Jara, 2013:356).

26 Intervención de un equipo de expertos escogidos por el Fondo Fiduciario (Martínez, 2014:351).

27 Aspecto de la "reparación adecuada" que contempla el Estatuto de Roma "las víctimas deben recibir reparaciones apropiadas, efectivas y rápidas en consonancia con la normativa internacional" (Jara, 2013:123) o "las víctimas deberán recibir reparaciones apropiadas, rápidas y adecuadas. Las reparaciones deberán ser proporcionales a los perjuicios, al sufrimiento, a las pérdidas y al daño resultante de los crímenes" (López Martín, 2013:273).

28 Se destaca "en la etapa de reparaciones" debido a que no fue así en la instancia propiamente penal: "muchas víctimas de crímenes sexuales no fueron consideradas víctimas ni reparadas, debido a la selectividad con la que actúa el sistema penal internacional" (Galian, 2014:391), exponiendo el concepto amplio de "víctima" en la instancia de reparaciones y el conflicto que presenta romper la causalidad delito condenado-consecuencia (López Martín, 
Cabe destacar que esta primera sentencia puso de manifiesto tanto la gravedad de las consecuencias de los crímenes que son juzgados ante sus estrados, como la importancia del Fondo Fiduciario en el cumplimiento de este objetivo de reparación adecuada de las víctimas pues, de otro modo, la insolvencia o insuficiencia económica del condenado (circunstancia posible dada la entidad económica de las reparaciones) tornaría en ilusoria es finalidad reparadora del sistema.

En este aspecto, habiendo sido declarado por la Corte como insolvente Lubanga, el Fondo Fiduciario representa el responsable exclusivo de aportar los recursos destinados a la reparación de las víctimas (Jara, 2013:125) se presenta como un aspecto conflictivo las medidas de reparación individual debido a que estas son exclusiva responsabilidad del condenado (regla 98), atenuando esta "exclusividad" en la medida que el existan los recursos sin comprometer la finalidad de reparación colectiva ${ }^{29}$. Así mismo, se resalta la importancia de la cooperación internacional (mediante el aporte de recursos al Fondo Fiduciario) como medida necesaria para garantizar el éxito de las medidas de reparación ante la posible insuficiencia de este patrimonio de común a todas las reparaciones (víctimas, medidas y casos), lo que puede derivar tanto en una implementación por etapas (supeditadas al ingreso de recursos) como en que nunca se efectivice las reparaciones dispuestas (Martínez, 2014:365-368).

La sentencia de reparación dictada por la Corte contiene un mandato genérico de reparar a las víctimas bajo los principios

\footnotetext{
2013:222) que redunda en la no reparación de víctimas de hechos sucedidos pero no juzgados (circunstancia presente en el caso). En este aspecto, se presenta como transversal a la función reparadora un correcto ejercicio de la acción penal tanto por la reparación tanto por el derecho de las víctimas a la verdad o que el crimen no quede impune (aspecto que resalta Galian), como por los límites que marca la relación condena-reparaciones.

29 "De ahí que en la resolución la Sala establece esas condiciones como requisitos para considerar y no para otorgar dichas compensaciones o indemnizaciones. En otras palabras, lo más probable es que el Fondo Fiduciario para las Víctimas no conceda indemnizaciones económicas a las víctimas, ya que previamente se ha pronunciado en contra de las reparaciones individuales." (Martínez, 2014:358).
} 
y objetivos expresados, estableciendo un plan de trabajo y delegando en el Fondo Fiduciario, además de la propia ejecución, la tarea de determinar el alcance y medidas específicas de reparación, estableciéndole la obligación de: (a) conformar el equipo técnico, (b) determinar las localidades/lugares beneficiarias, (c) consultar a las víctimas presentes, (d) determinar los daños (víctima, causalidad, entidad), (e) realizar debates públicos explicando los principios y procedimientos de reparación, (f) recoger las propuestas de reparación colectivas, y (g) presentar a la Sala interviniente el plan de reparaciones (Martínez, 2014:350-365).

En este aspecto, se destaca la delegación de funciones en el Fondo Fiduciario, reteniendo las funciones propiamente jurisdiccionales (aprobación de las medidas y control de la implementación), otorgándole ente un rol de gestión o auxiliar de materializar ese mandato genérico de $\operatorname{reparar}^{30}$ que convencional o reglamentariamente no se le asigne. Así mismo, se resalta que esta decisión introduce un diseño novedoso en tanto que contempla una participación amplia, informada y situada de los operadores que construyen el plan de reparación colectiva, así como posibles reparaciones individuales (principio de accesibilidad) de modo conjunto a una iniciativa propia del sistema en disponer las reparaciones que se observan como necesarias ${ }^{31}$.

En conclusión, la sentencia "Lubanga" "puede considerarse un bito en la bistoria del derecho penal internacional por

\footnotetext{
30 Se destaca que ya en las jurisdicciones nacionales (procesos colectivos) se profundiza sobre la delegación de diseño e implementación de reparaciones estructurales como un mecanismo que asegura la efectividad de la decisión, entendiendo que la retención por parte de la jurisdicción de todas las instancias de la construcción de la decisión o proceso de implementación atenta contra la propia efectividad de la sentencia (Verbic, 2017:354-357).

31 En este aspecto, la Corte Interamericana, la Corte Europea, el Comité de Derechos Humanos, así como los demás órganos convencionales emiten medidas de reparación a solicitud de parte, o bien un mandato genérico cuya implementación depende del voluntarismo estatal o la actividad de la víctima, sin una iniciativa de la jurisdicción en la construcción de las medidas de reparación. De igual modo, como se expresa en la nota al pie $n^{0} 17$, entre los tribunales internacionales que juzgan responsabilidad penal la máxima medida de reparación reconocida era la restitución de bienes.
} 
cuanto la reparación de la víctima es considerada por primera vez" (Galian, 2014:391), destacando el carácter amplio del concepto de víctima pasible de ser reparada en el marco de los procesos que tramitan ante la Corte Penal Internacional, la participación que se le reconoce a la víctima (complementado por un equipo de expertos) en la determinación de las medidas de reparación, que se presente en un proceso accesible (publicidad, información y situado en el territorio), así como el carácter amplio de las reparaciones dispuestas, que recepta directa o indirectamente la concepción interamericana de una reparación integral en la instancia internacional. Sin embargo, también se destaca el carácter genérico y programático de la sentencia, aspecto que genera cuestionamientos acerca de la efectividad de la decisión, así como las limitaciones económicas para su total realización, aspecto que se presenta como un elemento determinante (existencia de recursos) para la efectividad del sistema de reparaciones de la Corte Penal Internacional ${ }^{32}$.

\section{Apelación de la sentencia de reparación del caso "Lubanga"33}

El 03 de marzo de 2015 la Sala de Apelaciones de la Corte Penal Internacional se pronunció en las apelaciones contra la sentencia de primera instancia, modificando diferentes aspectos de su contenido, especialmente respecto del uso del Fondo Fiduciario como patrimonio de reparación de las víctimas, con

\footnotetext{
32 Debe tenerse presente que esta problemática se detecta en su primera sentencia principalmente por la extensión de las reparaciones a implementar, es decir, una insuficiencia de erogaciones a cargo del Fondo Fiduciario en una perspectiva intra-sentencia, sin embargo, también debe tenerse presente que la existencia de nuevas condenas, y por ende, nuevas medidas de reparación, puede generar esta insuficiencia en un plano inter-sentencias, es decir, la falta de recursos del Fondo Fiduciario para atender a todas las medidas de reparación dispuestas en los distintos casos, aspecto central a resolver tanto respecto de la disponibilidad de recursos, como en las pautas de asignación entre los diferentes casos, medidas de reparación y víctimas.

33 Nota: la sentencia y siguientes en análisis es traducida por el autor con sus limitaciones en el manejo del idioma de la sentencia.
} 
un "Anexo A"34 (párrafo 56) el cual disponía las modificaciones en la orden de reparación.

En este primer aspecto, la sentencia resalta que todas las reparaciones siempre deben dirigirse contra el condenado, efectivizada "a través" del Fondo Fiduciario, y no "por" el Fondo Fiduciario $^{35}$ (párrafo 76) incluso las de naturaleza colectiva ${ }^{36}$, siendo en caso de indigencia un adelanto de recursos por parte del Fondo bajo responsabilidad del condenado ${ }^{37}$, una interpretación que si bien evita la imposición de erogaciones al Fondo preserva la reparación de las víctimas.

Otro aspecto central de la decisión está dado por la necesidad de una vinculación entre la víctima/reparación con el crimen condenado $^{38}$, siendo obligatorio el determinar a las víctimas ${ }^{39}$ en la orden de reparación, entendiendo que esto repercute tanto

34 El contenido del anexo no se aparta sustancialmente en los principios y objetivos, destacando que la Sala de Apelaciones que además subsiste la reparación por los mecanismos nacionales u otras instancias internacionales (párrafo 4). El instrumento define a quienes se considera víctimas por las afectaciones sufridas, las medidas de reparación y las pautas para su correcta implementación (normas procesales ad hoc).

35 Establece el Reglamento del Fondo Fiduciario como elemento interpretativo para el alcance de las obligaciones del Fondo (párrafo 48)

36 "La Sala observa que (...) las reparaciones colectivas realizadas a través de Los fondos fiduciarios son "contra una persona condenada" (párrafo 72)

37 "En los casos en que la persona condenada no puede cumplir de inmediato Con una orden de reparación por razones de indigencia (...) el Fondo Fiduciario puede adelantar sus "otros recursos" de conformidad con regla 56 del Reglamento del Fondo Fiduciario, pero dicha intervención no exonerar a la persona condenada de responsabilidad. La persona condenada sigue siendo responsable y debe reembolsar al Fondo Fiduciario" (párrafo 115).

38 "La Sala de Apelaciones recuerda que solo las víctimas en el sentido de la regla 85 (a) de las Reglas de Procedimiento y Prueba y la regulación 46 de la Reglamento del Fondo Fiduciario, que sufrieron daños como resultado de la comisión de los crímenes de los cuales el Sr. Lubanga fue declarado culpable, pueden reclamar reparaciones contra Sr. Lubanga. De ello se deduce que cuando se otorga una indemnización por reparaciones en beneficio de una comunidad, solo los miembros de la comunidad que cumplan con los criterios relevantes son elegibles" (párrafo 211). En este sentido, la Sala establece reconoce que hay delitos que afectan a la comunidad en su conjunto, sin embargo, establece que la reparación colectiva tiene que estar definida en su composición y alcance en la orden de reparaciones (párrafo 212).

39 La determinación no implica individualización. En este sentido, la sentencia tiene que permitir identificar quienes revisten la condición de víctimas. 
en los derechos del condenado, como ellos propios derechos de las víctimas en tanto que impide impugnar la decisión (párrafo 181) procediendo la Sala a expresar cuales son las víctimas y daños acreditados (párrafo 191). En este aspecto, el vínculo de la reparación ordenada con el crimen condenado motiva la decisión de la Sala de excluir a las personas afectadas por violencia sexual de la condición de "víctimas" en el presente caso (párrafo 196), sin perjuicio de las asistencias que disponga el fondo ${ }^{40}$. Además, establece como obligatorio establecer en las sentencias los principios de las reparaciones ${ }^{41}$, así como identificarse las modalidades de reparación más adecuadas ${ }^{42}$ (párrafo 200).

Finalmente, se resalta que, ante una apelación de la defensa fundada en la jurisprudencia del Tribunal Europeo de Derechos Humanos respecto de la causalidad entre el crimen y la obligación de reparar, la Sala de Apelaciones contrasta la decisión con los estándares de la Corte Interamericana (párrafos 127-128). En este aspecto, si bien la sentencia hacia la distinción entre responsabilidad estatal y responsabilidad individual, y rechaza la apelación, puede observarse la jurisprudencia de estas instancias internacionales es receptada por todas las instancias de la Corte Penal Internacional.

\section{La reparación de las víctimas en el caso "Katanga"}

El 24 de marzo de 2017 la Sala de Primera Instancia II dicta la sentencia "Orden de reparaciones de conformidad con el

\footnotetext{
40 "La conclusión anterior en relación con la responsabilidad del Sr. Lubanga por las reparaciones con respecto del daño resultante de la violencia sexual y de género no debe verse como impedir que esas víctimas puedan beneficiarse de las actividades de asistencia que el Fondo Fiduciario puede emprender" (párrafo 199) sin perjuicio que la Sala aclara en su sentencia que estas erogaciones provenientes de "otros recursos" son decisión de las autoridades del Fondo y no de las Salas (párrafo 111).

41 "La Sala de Apelaciones considera que el requisito de establecer principios en relación con las reparaciones es obligatorio ("deberá") (...) La Sala de Apelaciones considera que esto también se aplica a la reparación individual" (párrafo 52).

42 Se destaca que la Sala no considera que exista un derecho humano internacionalmente reconocido a la "reparación individual" (párrafo 154-155).
} 
artículo 75 del Estatuto en el caso "El Prosecutor v. Germain Katanga", quien había sido condenado por crímenes de guerra y lesa humanidad por ataques contra población civil (asesinato, ataque a civiles no intervinientes, destrucción de propiedad y saqueo), así como absuelto por los cargos de explotación sexual, violación y uso de niños soldados.

Debe resaltarse respecto de la decisión que la Sala ordena previo a su emisión, la sustanciación de un proceso de determinación de las víctimas, construcción y propuesta de las medidas de reparación a cargo de un representante común de las víctimas $^{43}$ (representación unificada), el Fondo Fiduciario y la defensa $^{44}$ (párrafos 3-12).

El primer aspecto que se aborda en la sentencia es la condición de víctima en el marco de la reparación, recuperando los estándares fijados por la Sala de Apelaciones en el caso "Lubanga", los cuales establecen un carácter más restrictivo que la sentencia de primera instancia, en tanto que:

(a) la víctima indirecta es considera como tal en tanto haya un nexo causal a través de la víctima directa. ${ }^{45}$

(b) se requiere un nexo causal entre el daño sufrido y el delito condenado ${ }^{46}$ (párrafos 36-37).

43 "en la etapa de reparación, las víctimas y los condenados persona se emite en la posición de las partes en el procedimiento" (párrafo 15).

44 Puede observarse una recepción de las pautas para la orden de reparación, ante lo cual la Sala de primera instancia sustancia un proceso previo de consulta y construcción de las propuestas.

45 "La Sala de Apelaciones de Lubanga sostuvo que las reparaciones están intrínsecamente vinculadas a la persona cuya responsabilidad penal se establece en una condena y cuya culpabilidad por esos actos criminales se determina en una frase" (párrafo 31).

46 Confirmando las observaciones realizadas por Galian (nota al pie $\left.n^{0} 28\right)$. En este aspecto, la Sala de Apelaciones sostuvo un criterio que excluya a las víctimas de violencia sexual en el caso "Lubanga" de poder comparecer como víctimas a instancias de la reparación pero sostuvo una inclusión "humanitaria" que perjudica a las víctimas en tanto que depende de un voluntarismo de terceros y no un reconocimiento del derecho humano a la reparación que la propia Corte reconoció: "Es apropiado que la Junta Directiva del Fondo Fiduciario considere, en su discreción, la posibilidad de incluir víctimas de violencia sexual y de género en Las actividades de asistencia realizadas de conformidad con su mandato en virtud de la regla 50 
(c) es carga del reclamante acreditar su condición de víctima, daño y nexo causal, aunque se contempla una atenuación en los criterios valorativos (párrafos 41, 47-49).

Asimismo, la Sala procede a evaluar los daños reclamados y/u observados efectuando un análisis de admisibilidad de los mismos respecto de su condición de daño exigible, nexo causal con los crímenes condenados, y mérito sobre la prueba que los acredita.

En este aspecto, dentro de los daños evaluados se destaca el análisis del daño sui generis generado por traslados forzados, pérdida de oportunidades y/o afectación a la a calidad de vida (párrafo 138-139) como daño reparable, así como del daño intergeneracional ocasionado por los crímenes (párrafo 134-135), sin perjuicio de su rechazo por falta de prueba, especialmente porque, recuperando estándares de la jurisprudencia interamericana en materia de reparación de víctimas de masacres (párrafo 231), se presentan como afectaciones pasibles de reparación dentro del sistema de la Corte Penal Internacional.

La sentencia aborda las solicitudes de reparación de las violencias sexuales (párrafos 140-154) y los niños soldados (párrafos 155-161), las cuales son rechazadas como víctimas recurriendo a los estándares la apelación de "Lubanga", por lo que estas reparaciones son delegadas en el mandato de asistencia del Fondo Fiduciario $^{47}$, marcando que el sistema ofrece reparaciones en tanto se logre una condena específica por hecho generador.

Uno de los aspectos más relevantes de la sentencia es el abordaje de la reparación colectiva, estableciendo como tales a las que se dirigen a un grupo o categoría definido no por el crimen, sino por la existencia de un daño compartido ${ }^{48}$, sin

\footnotetext{
a) de Reglamento del Fondo Fiduciario." (Sala de Apelaciones "Anexo A: orden de reparación (modificado)" 03/03/2015, párrafo 64).

47 "la Sala invita al TFV a considerarlo como parte de su mandato de asistencia, siempre que sea posible, a estos solicitantes" (párrafo 254). En este sentido, se recepta la autonomía y discrecionalidad de las autoridades del Fondo que estableció la Sala de Apelaciones en "Lubanga".

48 "El crimen per se no puede ser la piedra de toque definir un grupo al que se le puedan otorgar reparaciones. El quid de lo colectivo las reparaciones radican en la percepción de los miembros
} 
requisitos de personalidad jurídica, afectación un derecho colectivo, destacando que incluso pueden dirigirse a individuos mientras beneficien al colectivo ${ }^{49}$ (párrafos 276-278). En este sentido, la Corte diferencia entre "reparaciones comunitarias" (comunes a todos ej. la construcción de un hospital) de "reparaciones individualizadas" en tanto que la reparación colectiva contempla la necesidad particular de cada víctima que integra el colectivo (párrafos 279-280).

Así mismo, recuperando la jurisprudencia de distintos tribunales internacionales, la sentencia establece que la reparación individual no es accesoria o reemplazable por las medidas de reparación colectiva ${ }^{50}$, reafirmando el respeto a la persona a través del reconocimiento de su individualidad en el marco de las reparaciones (párrafos 281-295), así como el propio carácter reparador de la participación de la víctima "en" el proceso de reparación, revalorizando la participación de la víctima y su accesibilidad. En consecuencia, las medidas de reparación dispuestas son, en el plano individual una compensación simbólica de USD 250 (párrafo 300), así como en el plano colectivo (a) apoyo para la vivienda, (b) apoyo en el desarrollo de una actividad económica, (c) apoyo en educación, y (d) asistencia psicológica ${ }^{51}$ (párrafo 304).

del grupo que experimentaron daño compartido En consecuencia, la Sala determina que los premios colectivos pueden ser hecho solo donde las víctimas se perciben como si hubieran sufrido un daño compartido." (párrafo 275).

49 El entender posibles reparaciones individuales como colectivas por su finalidad o impacto social/comunitario permite ingresarlas a las reparaciones a cargo del Fondo Fiduciario sin necesidad de ingresar a discutir eventuales obligaciones a cargo del Fondo en materia de reparaciones individuales, como hace la sentencia en uno de sus apartados.

50 "La Sala también presta (...) que argumentan que las reparaciones colectivas pueden ser adicionales a, pero no en lugar de reparaciones individuales. (...) Pasando específicamente a las reparaciones individuales, la Sala toma nota (. . .) que los tribunales nacionales y la justicia de transición los mecanismos han ordenado reparaciones individuales, incluso donde grandes cantidades de las víctimas estuvieron involucradas" (párrafos 283-284). Es interesante observar que la Corte recupera experiencias nacionales, práctica presente en la jurisprudencia interamericana.

51 Puede observarse la aplicación de esta lógica de reparación comunitaria (principalmente en las medidas de reparación educativas) de las medidas colectivas individualizadas, como 
Cabe destacar que, retomando la apelación de "Lubanga", se establece la responsabilidad patrimonial del imputado (sin perjuicio de su insolvencia), determinándola en USD 1.000.000 (párrafos 245 y 264) así como la entidad final de los daños en USD 3.752.620. En este sentido, la sentencia extiende la responsabilidad de las reparaciones individuales al Fondo Fiduciario, entendiendo que la misma es una carga accesoria propia de su naturaleza humanitaria para con las víctimas. ${ }^{52}$

Por último, la decisión expresa que las reparaciones pueden adoptar otras modalidades de reparación apropiadas (no contempladas expresamente en el Estatuto de Roma), como las de valor simbólico, preventivo o transformador ${ }^{53}$ (párrafo 296), y recupera la responsabilidad estatal como otra fuente de reparación del as víctimas afectadas ${ }^{54}$.

\section{La reparación de las víctimas en el caso "Al Mahdi"}

El 17 de agosto de 2017 la Sala de Primera Instancia VIII dicta la sentencia "orden de reparaciones" a partir de la condena a Al Mahdi por el crimen de guerra de atacar edificios protegidos (art. 8 inc. 2.e) tras la sustanciación de un proceso previo similar al del caso "Katanga". En este aspecto, es la

lo es el apoyo en vivienda o asistencia psicológica. Puede observarse que estas medidas se construyen a través de la participación de las víctimas, así como se determinó no disponer medidas de memoria por expresa oposición de estas (párrafo 301).

52 "A juicio de la Sala, la discreción para otorgar reparaciones individuales, cuando se cumplen las condiciones, se aplica independientemente de la situación financiera del Persona responsable de las reparaciones. (...), la Sala no ve ninguna disposición en el Reglamento para prohibir a la Junta Directiva del TFV administrar sus recursos para complementar las reparaciones individuales, incluso si el Reglamento no establece tal obligación" (párrafos 335 y 337).

53 En consonancia con la jurisprudencia de la Corte Interamericana (en tanto que la propia sentencia recupera sus estándares en materia de reparaciones) podría entenderse además de reconocer la procedencia de medidas de satisfacción se está reconociendo la posibilidad de disponer medidas de no repetición.

54 “Debe señalarse que el artículo 75 (6) del Estatuto establece: "Nada en este artículo se interpretará como perjudicial para los derechos de las víctimas bajo o el derecho internacional". Una orden de reparación no exime, por lo tanto, a los Estados Partes responsables de otorgar reparaciones a las víctimas de conformidad con otros tratados o legislación nacional" (párrafo 323). 
primera sentencia de reparaciones que específicamente aborda la reparación del patrimonio cultural motivo por el cual la Corte procede a analizar el bien jurídico tutelado.

Resalta la Corte que la vida cultural se encuentra comprendida dentro de los derechos humanos reconocidos internacionalmente, así como la comunidad internacional condenó su destrucción, resaltando tanto su importancia como elemento identitario $^{55}$ (párrafo 14), así como su composición tanto de elementos materiales como inmateriales ${ }^{56}$, adoptando un concepto amplio de "patrimonio cultural". En este sentido, la decisión expresa se configura esta afectación identitaria ${ }^{57}$, así como que los bienes culturales por su particular naturaleza no son fungibles, manifestando que su destrucción contiene "un mensaje de terror" (párrafo 22) hacia la población.

Desde este posicionamiento, la Sala ingresa a considerar las reparaciones del presente caso retomando los estándares fijados en la sentencia de la Sala de Apelaciones del caso "Lubanga", resaltando su recepción en la sentencia "Katanga" (párrafos 25 y 26), generando una continuidad en su jurisprudencia en materia de reparaciones $^{58}$, recuperando como principio la adecuación a la cultura y costumbre local de las reparaciones, así como su necesidad

\footnotetext{
55 Interviene en el proceso la UNESCO como amicus curiae.

56 "Debe entenderse que el patrimonio cultural abarca los recursos que permiten identificación cultural y procesos de desarrollo de individuos y grupos, que ellos, implícita o explícitamente, desean transmitir a las generaciones futuras. e incluye patrimonio tangible compuesto de sitios, estructuras y restos de valor arqueológico, histórico, religioso, cultural o estético, así como patrimonio inmaterial que comprende tradiciones, costumbres y prácticas, conocimiento, lenguajes vernáculos u otros, formas de expresión artística y folklore. El patrimonio cultural es considerado internacionalmente importante independientemente de su ubicación y origen" (párrafo 15)

57 "El ataque contra los edificios protegidos no solo destruyó y dañó estructuras físicas. Su impacto se extendió a la comunidad y disminuyó el vínculo y la identidad que tenía la comunidad local con tan valiosa cultura patrimonio" (párrafo 19).

58 Puede observarse que las sentencias de reparación en el caso "Al Mahli" y "Katanga" se remiten en sus fundamentos repetidamente a la jurisprudencia previa (Apelación de "Lubanga" o "Katanga") reafirmándose a sí misma en una técnica similar a la Corte Interamericana. En este aspecto, se podría entender que el Corte intenta consolidar una jurisprudencia coherente y sostenida en el tiempo.
} 
de un enfoque de género en el acceso al patrimonio cultural ${ }^{59}$ (párrafo 34). Así mismo, se reafirma la obligación de los estados de reparar a las personas bajo su jurisdicción según las obligaciones emanadas del derecho interno y los tratados (de derechos humanos), así como cooperar en el proceso de reparación ${ }^{60}$ (párrafo 36).

La sentencia recupera el estándar de "víctima" de la apelación de "Lubanga" aclarando que el daño puede ser indirecto, pero que debe ser personal, que en el caso de las organizaciones "deben demostrar un daño directo a sus propiedades" y que la situación económica de la población no es relevante a efectos de determinar el daño moral (párrafo 44). En este sentido, recuperando las categorías desarrolladas en "Katanga", dispone como medidas de reparación ${ }^{61}$ :

(a) individuales:

(a.1) indemnización de las personas que dependían económicamente de los edificios afectados.

(a.2) compensación del daño moral a quienes tienen un antepasado enterrado en los sitios afectados.

(b) colectivas:

(b.1) reparación y mantenimiento de las estructuras: medida de no repetición. ${ }^{62}$

\footnotetext{
59 Se destaca este posicionamiento debido a que reafirma el principio de no discriminación y respeto de la dignidad de las personas (mujeres especialmente) el cual debería sostenerse en la implementación de medidas de reparación por sobre la discriminación o estereotipos culturales (la reparación no respeta o tutela la discriminación de la mujer aun cuando sea tradición, costumbre, creencia o "cultural").

60 Puede observarse que la Corte manifiesta el carácter complementario del sistema de la Corte Penal Internacional a los nacionales e internacionales que juzguen responsabilidad estatal.

61 La sentencia habla de "víctimas relevantes" debido a que por el propio concepto de patrimonio cultural el carácter de víctima es omnicomprensivo: "La Sala ha concluido que la destrucción de los edificios protegidos afectó no solo las víctimas directas de los crímenes, es decir, los fieles y habitantes de Tombuctú, pero también personas en todo Malí y la comunidad internacional" (párrafo 51). En este aspecto, la propia Corte establece que hay víctimas que sufrieron de modo más grave esta afectación (habitantes), así como resalta que no hay solicitudes de reparación a nombre de la comunidad internacional (párrafo 52).

62 Observando que la UNESCO reparó las estructuras expresamente se dispone como medida de reparación el acondicionar las estructuras para evitar un nuevo ataque (medida de no
} 
(b.2) rehabilitación económica de la comunidad de Tombuctú por el daño económico. ${ }^{63}$

(b.3) reparación colectiva del daño moral/espiritual a través de medidas de rehabilitación ${ }^{64}$.

(b.4) entrega de un dólar al Estado de Malí como medida simbólica (párrafo 106).

(b.5) entrega de un dólar a UNESCO como medida simbólica a favor de la humanidad (párrafo 107).

(b.6) Difusión del video de disculpa de Al Mahdi. ${ }^{65}$

Finalmente, existiendo daños no probados o sin relación causal con los crímenes condenados, se invita al Fondo Fiduciario a implementar medidas de asistencia respecto de las personas afectadas (párrafo 108).

Como se observa, el presente caso es paradigmático debido a que la afectación por el crimen condenado es al patrimonio cultural, motivo por el cual repercute en la identidad de la población (así como se considera afectada a la humanidad en su conjunto), lo que implica un daño que escapa a los métodos tradicionales de reparación en instancias internacionales pues la compensación económica no lograr la reparación de una afectación identitaria, resaltándose la importancia de las medidas simbólicas a efectos de restaurar ese elemento dañado en la comunidad.

repetición), resaltando el respeto de las personas en esa adecuación: “La Sala enfatiza que estas reparaciones deben adaptarse a las preocupaciones individuales con respecto a cada uno de los edificios protegidos" (párrafo 67).

63 Puede observarse que mientras algunas víctimas tienen una reparación individual (a.1) la Corte dispone medidas colectivas "individualizadas" como pueden ser microcréditos u otras medidas (párrafo 83), recuperando tácitamente la doctrina de la Sala de Apelaciones en "Lubanga" sobre la inexistencia de un derecho humano reconocido a la reparación individual.

64 Destaca la importancia de las medidas simbólicas.

65 Entendiendo que la disculpa es genuina, la sentencia ordena su difusión entendiendo su potencial reparatorio para las víctimas y que corresponde al fuero interno de cada persona decidir si a modo personal si lo entiende suficiente (párrafos 68-71). 
Así mismo, si bien hubo medidas de índole económica o que implican un desembolso de recursos financieros (la responsabilidad de Al Mahdi se estableció en USD 2.700.000) las estructuras se encontraban reparadas por la UNESCO, sin perjuicio que las consecuencias de los crímenes subsistían debido a que trascendieron la dimensión material de las estructuras. En este aspecto, si bien la Corte Interamericana tiene un desarrollo en medidas de reparación (Bruno, 2013:55) la propia naturaleza de los crímenes competencia de la Corte Penal Interamericana se presenta como un ámbito propicio para la construcción de estándares en materia de reparaciones propicios para una mejor recomposición de las víctimas (afectadas colectivamente) que pueden proyectarse hacia las demás instancias internacionales y/o nacionales.

\section{Conclusiones}

A modo de conclusión, la víctima y su dignidad se presenta como un actor y elemento de sentido transversal a todo el sistema derivado del Estatuto de Roma, el cual recupera al derecho internacional de los derechos humanos como una fuente de derecho, así como la jurisprudencia de sus tribunales internacionales como una interpretación de ese derecho que integra al Estatuto.

En este sentido, la recepción expresa de estándares de la Corte Interamericana y de la Corte Europea de Derechos Humanos, además de aprovechar el camino recorrido por estos tribunales internacionales, incorpora a la Corte Penal Internacional en el diálogo de estas instancias jurisdiccionales y la construcción del corpus iuris de los derechos humanos a partir de concepción común de la preeminencia de la dignidad de la persona.

Cabe destacar que la Corte Penal Internacional presenta este juego en dos sentidos, asegurar el debido proceso del imputado, así como recomponer a las víctimas de los crímenes que persigue. Esta particular naturaleza se presenta como una limitación en la reparación de las víctimas (sin que implique cuestionar el carácter imperativo del debido proceso), y resalta la importancia 
de un correcto ejercicio de la acción penal, especialmente con perspectiva de género.

Así mismo, un aspecto central en la reparación de las víctimas está marcado por la disponibilidad de recursos económicos para afrontar las reparaciones, siendo el Fondo Fiduciario un instrumento importante para lograr una reparación, pero que puede presentarse como insuficiente, resaltando la Corte Penal Internacional (entiende el autor que con acierto) que, además de requerir la cooperación internacional para recomponer a las víctimas de los crímenes que atentan contra la humanidad que la propia comunidad internacional decidió perseguir, el sistema debe ser complementario a las instancias de reparación nacional, regional e internacional, siendo un elemento imprescindible efectivizar la responsabilidad estatal frente a las víctimas.

Es importante resaltar el concepto amplio de víctima que presenta la jurisprudencia de la Corte Penal Internacional, así como de daño reparable, en una concepción pro persona, complementada por el principio de accesibilidad que maneja el sistema: acción situada en el territorio, contacto con las víctimas, publicidad e información de las posibilidades y mecanismos de reparación, así como la posibilidad de intervenir o peticionar en los procesos de reparación.

Por último, se recupera las similitudes del proceso de reparación con los procesos colectivos (civiles) de las jurisdicciones locales por lo paradigmático del sistema de la Corte Penal Internacional que aborda la reparación de casos complejos con gran cantidad de víctimas y daños de distinta índole, siendo un modelo u experiencia a recuperar en los ámbitos internos en la construcción de procesos que puedan dar respuesta a las víctimas.

\section{Bibliografía}

Bruno, R. C. (2013). "Las medidas de reparación en la jurisprudencia de la Corte Interamericana de Derechos Humanos: alcances y criterios para su determinación" (Tesis de maestría inédita). Universidad Nacional de La Plata. 
Galian, P. (2014). “"Modalidades de reparación y adecuación al tipo de víctima". En "Análisis de la primera sentencia de la corte penal internacional: el caso lubanga" (389-430). Colombia: Konrad Adenauer Stiftung.

Ibañez Rivas, J. M. (2014). Artículo 25. En "Convención Americana Sobre Derechos Humanos - Comentario"(608-653). Colombia: Konrad Adenauer Stiftung.

López Martín, A. G. (2013). "Primera sentencia de la Corte Penal Internacional sobre reparación de las víctimas: caso The Prosecutor c. Thomas Lubanga Dyilo. 7 de agosto de 2012". Revista Española de Derecho Internaciona, LXV/2, 209-226.

Nader, A. (2014). "Disclosure e integridad procesal en el caso lubanga. el respeto de las reglas procesales y la fundamentación del derecho penal internacional". En "Análisis de la primera sentencia de la corte penal internacional: el caso lubanga" (63106). Colombia: Konrad Adenauer Stiftung.

Martínez Ventura, J.E. (2014). "Análisis del caso Lubanga. el procedimiento de reparaciones". En "Análisis de la primera sentencia de la corte penal internacional: el caso lubanga" (343-376). Colombia: Konrad Adenauer Stiftung.

O'Donell, D. (2012). "Derecho Internacional de los Derechos Humanos: normativa, jurisprudencia y doctrina de los sistemas universal e interamericano,". México: Tribunal Superior de Justicia del Distrito Federal.

Olásolo, H. \& Kiss, A. (2010). "El Estatuto de Roma y la Jurisprudencia de la Corte Penal Internacional en Materia de Participación de Víctimas". Revista Electrónica de Ciencia Penal y Criminología, 12-13, 13:1-13:37.

Olásolo H. \& Galain, P. (2010) "La Influencia en la Corte Penal Internacional de la Jurisprudencia de la Corte Interamericana de Derechos Humanos en materia de acceso, participación y reparación de víctimas". En "Sistema interamericano de protección de los derechos humanos y derecho penal internacional" (379-426). Colombia: Editorial Temis.

Verbic, F. (2017). "Manual de Introducción a los Procesos Colectivos y las Acciones de Clase". En "Diálogo Multidisciplinario sobre la Nueva Justicia Civil de Latinoamérica" (219-379). Chile: Centro de Estudios de las Américas. 